\title{
EFL Lecturers' Metadiscourse in Chinese University MOOCs Across Course Types
}

\section{Dongyun Zhang ${ }^{1} \cdot$ Diyun Sheng ${ }^{2}$}

Received: 18 February 2020 / Accepted: 7 January 2021 / Published online: 27 January 2021

(c) The Author(s), under exclusive licence to Springer Nature Switzerland AG part of Springer Nature 2021

\begin{abstract}
With the spread of COVID-19 in China at the beginning of 2020, MOOCs, as a kind of currently popular online learning resource, have played a dominant role in higher education field. However, chiefly focusing on teaching organization and learning process in MOOCs, previous studies have paid inadequate attention to lecturers' discourse. In order to provide some useful views on this issue, this study investigates EFL lecturers' metadiscourse in Chinese university MOOCs to sketch its distinctive pattern across course types. Based on a self-built corpus, this research adopted interpersonal model as theoretical foundation and analyzed the frequency and functions of metadiscourse by AntConc 3.5.7 and IBM SPSS 23. Findings suggest that specific educational context in MOOCs leads to low frequency of metadiscourse and its use is mainly aimed at the enhancement of intelligibility, reliability, and interactivity. Besides, course types with different knowledge structures also exert certain influence on metadiscourse usage. Course types focusing on procedural knowledge (i.e. the knowledge related to practical process) tend to apply metadiscourse to enhance intelligibility and interactivity, while the ones stressing declarative knowledge (i.e. the knowledge related to explicit facts) attach more importance to reliability. Lastly, the paper concludes with implications for EFL lecturers' metadiscourse in Chinese university MOOCs.
\end{abstract}

Keywords Metadiscourse - Lecturers' discourse - Chinese university MOOCs · Course types

\section{Abbreviations}

GenP English for General Purposes

OccuP English for Occupational Purposes

SpecS English for Specific Skills

Diyun Sheng

sdy@shnu.edu.cn

1 Shanghai Jincai North Secondary School, 555 Miaopu Road, Shanghai 200135, China

2 Foreign Languages College, Shanghai Normal University, 100 Guilin Road, Shanghai 200234, China 
AcadC English for Academic Courses

CultC English for Cultural Communication

\section{Introduction}

At the beginning of 2020, the outbreak of highly contagious COVID-19 in China has been commencing Massive Open Online Courses (MOOCs) with considerable attentiveness because of its great advantage of liberating education from geographical restriction. Compared with academic lectures and classroom teaching, MOOCs are featured by higher openness, briefer lectures, the invisibility of learners, and learners' subjective initiative as chief driving force. Meanwhile, among Chinese MOOCs, there are a certain number of EFL courses where lecturers' discourse works as both the object of study and the vehicle of teaching (Nunan 1991: 189). Thus, it is believed that in these MOOCs, lecturers' discourse will present a distinctive pattern, especially in metadiscourse, because it plays an important role in enhancing learners' comprehension and involvement in 'monologic' MOOCs.

However, most previous metadiscourse studies focus on written register from cross-linguistic (Dafouz-Milne 2008; Mur-Dueñas 2011; Kuhi and Mojood 2014; $\mathrm{Mu}$ et al. 2015) and cross-disciplinary perspective (Hyland and Tse 2004; Cao and $\mathrm{Hu}$ 2014; Hu and Cao 2015; Hyland and Jiang 2018), which have found that both linguistic and disciplinary context can exert influence on metadiscourse choice and that even in the same disciplinary domain, there are marked variations (Khedri et al. 2013; Cao and $\mathrm{Hu}$ 2014; Hu and Cao 2015). Recently, increasing interest has appeared in spoken register (Mauranen 2010; Ädel 2012; Ágnes 2012; Zhang et al. 2017). Some studies on classroom discourse (Ädel 2012; Lee and Subtirelu 2015) have revealed that pedagogical focus can influence metadiscursive usage and so can gender and discipline, especially in intensifiers (Liu 2019). However, these studies on classroom metadiscourse are still far from enough, let alone that in MOOCs.

Inspired by previous research and currently under-represented research on metadiscourse in MOOCs, this study is aimed to find out the general pattern of EFL lecturers' metadiscourse in Chinese university MOOCs and differences among different course types to help EFL lecturers establish more efficient lecturer-learner relationship.

\section{Literature Review}

\section{Theoretical Research on Metadiscourse}

Coined by Zellig Harris in 1959, the term "metadiscourse" has aroused much interest in applied linguistics with two approaches emerging: non-integrative and integrative approach (Mauranen 2010: 17). The former approach chiefly stresses textual reflexivity in the organization and cohesion of articles while the latter values both textual reflexivity and textual interaction with the aim to build affiliation among the three key elements including writer, reader, and text (Hyland 2005a: 63-65). As one 
of the representative scholars for this approach, Ken Hyland strongly emphasizes the metadiscursive function of expressing the author's stance and engagement in social interaction. Thus, he defines metadiscourse as "the cover term for the self-reflective expressions used to negotiate interactional meanin gs in a text, assisting the writer (or speaker) to express a viewpoint and engage with readers as members of a particular community" (2005a: 37). Moreover, based on his own works on an interactional model of stance and engagement (2005b) and specific categories including hedges (1996), addressee features (2001), and directives (2002), Hyland has put forward interpersonal model (Hyland and Tse 2004; Hyland 2005a), a systematic and practical framework with important contribution to metadiscursive research. Thus, with the aim to stress both textual and interactional function in EFL lecturers' metadiscourse, Hyland's model is adopted here as the fundamental framework to find out the relationship among lecturers, imagined learners, and course content in MOOCs.

\section{Empirical Research on Metadiscourse}

Currently, most studies are contrastive analysis on research articles (RAs) (Gillaerts and Velde 2010; Mur-Dueñas 2011; Mu et al. 2015; Kawase 2015), university students' writing (Intaraprawat and Steffensen 1995; Li and Wharton 2012; Hong and Cao 2014; Lee and Casal 2014; Lee and Deakin 2016; Ho and Li 2018), news media (Dafouz-Milne 2008; Kuhi and Mojood 2014; Fu and Hyland 2014) and business communication (Mauranen 1993; Vergaro 2005; Vásquez 2015). Among them, one of the focuses is cross-disciplinary study, with Hyland as the representative. His investigation on 240 graduate dissertations from six disciplines (Hyland and Tse 2004; Hyland 2004, 2005a, 2010) found that soft knowledge disciplines (e.g. applied linguistics, business studies) adopt more metadiscourse, especially more hedges, attitude markers, and self mentions, than hard knowledge disciplines (e.g. computer science, biology), possibly because of the tendency on explicit personal interpretation in the former disciplinary domain. Furthermore, there are several specific disciplines divergent from the general pattern of their corresponding disciplinary domain. This suggests that no matter in the comparison among different broad disciplinary domains or specific disciplines affiliated to the same domain, there are both similarities and differences in metadiscourse usage. Similarly, other researchers (Khedri et al. 2013; Cao and $\mathrm{Hu} 2014$; $\mathrm{Hu}$ and Cao 2015) have put forward that metadiscourse usage can be influenced by distinctive knowledge organization of disciplines, social authorization and contextual restriction in soft disciplines. Apart from synchronic research, diachronic research (Hyland and Jiang 2018) has also presented a changing pattern of metadiscourse in soft knowledge and science subjects. Building on this line of research, this study believes that there will be differences across course types with different knowledge structures.

Recently, more scholars have turned to spoken mode, such as student's seminars (Mauranen 2010) and course presentation (Ágnes 2012), and differences across spoken registers (Zhang et al. 2017). However, the study on metadiscourse in teacher discourse is far from enough. Lee and Subtirelu (2015) has paid attention to this issue and proposed that metadiscourse in classroom is inextricably linked to teaching 
objectives and content. For instance, L2 teachers in English for Academic Purposes (EAP) lessons use more metadiscourse (especially frame markers and engagement markers) to facilitate the negotiation with non-native students. Comparatively, teachers in university lectures tend to use more transition markers to help learners grasp logical relationship of arguments and gain disciplinary knowledge.

In brief, although current metadiscursive research covers cross-disciplinary divergence and classroom discourse, how teachers' metadiscourse is influenced by typical features of MOOCs and different course types still remains to be solved. Thus, this research sets out to answer the two questions:

1. What is the general distribution of EFL lecturers' metadiscourse in Chinese university MOOCs?

2. What are the differences in EFL lecturers' metadiscourse across course types from the perspective of frequency and function?

\section{Methodology}

\section{Analytical Framework Based on Hyland's Interpersonal Model}

Hyland's interpersonal model (Hyland 2005a: 49; Hyland and Tse 2004: 169) is composed of both interactive and interactional dimension involving ten categories.

\section{Interactive Metadiscourse}

- Transition markers indicate the relations between clauses.

- Frame markers present the advancing direction of discourse.

- Endophoric markers are used to make other parts of discourse salient.

- Evidentials provide intertextual support.

- Code glosses elaborate previous discourse more clearly.

\section{Interactional Metadiscourse}

- Hedges withhold commitment and open up dialogue.

- Boosters emphasize certainty or close dialogue.

- Attitude markers express speaker's attitude chiefly towards discourse.

- Self mentions explicitly refer to the author herself / himself.

- Engagement markers explicitly refer to the audience's presence.

For in-depth analysis in this study, the original model has been further revised as shown in Table 1 (specific examples in context can be found in "Results and Discussion" section).

Engagement markers by directives are further divided into four sorts (Hyland 2002) as follows: 
Table 1. Theoretical framework based on Hyland's interpersonal model

\begin{tabular}{|c|c|c|c|}
\hline Category & Sub category & Examples & Code \\
\hline \multirow[t]{3}{*}{ Transition markers } & For addition & moreover, and, besides & $<\operatorname{Tad}>$ \\
\hline & For comparison & but, however, similarly & $<T c m>$ \\
\hline & For consequence & because, so, thus & $<T c n>$ \\
\hline \multirow[t]{4}{*}{ Frame markers } & For sequencing & first, one, then & $<F s e>$ \\
\hline & For labelling stages & to sum up, so far & $<F s t>$ \\
\hline & For announcing goals & will, want & $<F g o>$ \\
\hline & For shifting topic & turn to, now, so & $<F t p>$ \\
\hline Endophoric markers & / & above; in the following & $<E d M>$ \\
\hline Evidentials & / & according to $X ; Z$ states & $<E v i>$ \\
\hline \multirow[t]{3}{*}{ Code Glosses } & By examples & for example, such as & $<C e>$ \\
\hline & By defining & which means, refer to & $<C d>$ \\
\hline & By rephrasing & in other words; that is (to say) & $<C r>$ \\
\hline Hedges & / & might; perhaps; possible; about & $<H>$ \\
\hline Boosters & / & in fact; definitely; it is clear that & $<B>$ \\
\hline Attitude markers & / & unfortunately; surprisingly; agree & $<A>$ \\
\hline Self mentions & / & I; my; me; we (exclusive) & $<$ Sem $>$ \\
\hline \multirow[t]{4}{*}{ Engagement markers } & By questions & wh- $Q$, yes/no- $Q$, minimal $Q$ & $<E g q>$ \\
\hline & By directives & look, ask, consider, remember & $<E g d>$ \\
\hline & By first person & we, our, us (inclusive) & $<E g f>$ \\
\hline & By second person & you, your, yourself & $<E g_{S}>$ \\
\hline
\end{tabular}

i. Referential acts refer learners to specific items aiding interpretation and sometimes informing them of the following activities. (e.g. look, see, watch, talk about, get to know)

ii. Physical acts instruct learners to perform acts related to real-world. (e.g. ask, make, check, practice, decide)

iii. Cognitive acts prompt learners to think about content independently or leading them to understand a point in a certain way. (e.g. think about, consider, imagine, find out, identify)

iv. Emphatic acts arouse learners' attention to critical points. (e.g. notice, keep in mind, remember, pay attention to).

\section{Corpus}

The general pattern of metadiscourse in MOOCs has been reflected by a self-built 100,933-word corpus (The Corpus of Chinese University MOOCs, CCUM) consisting of lectures conveyed by 45 EFL lecturers from 20 Chinese top universities which are distributed in central and coastal provinces in China (Fig. 1). These courses are all collected from the mainstream MOOC learning websites, including Chinese University MOOC (www.icourse163.org) operated by Netease and Higher Education 


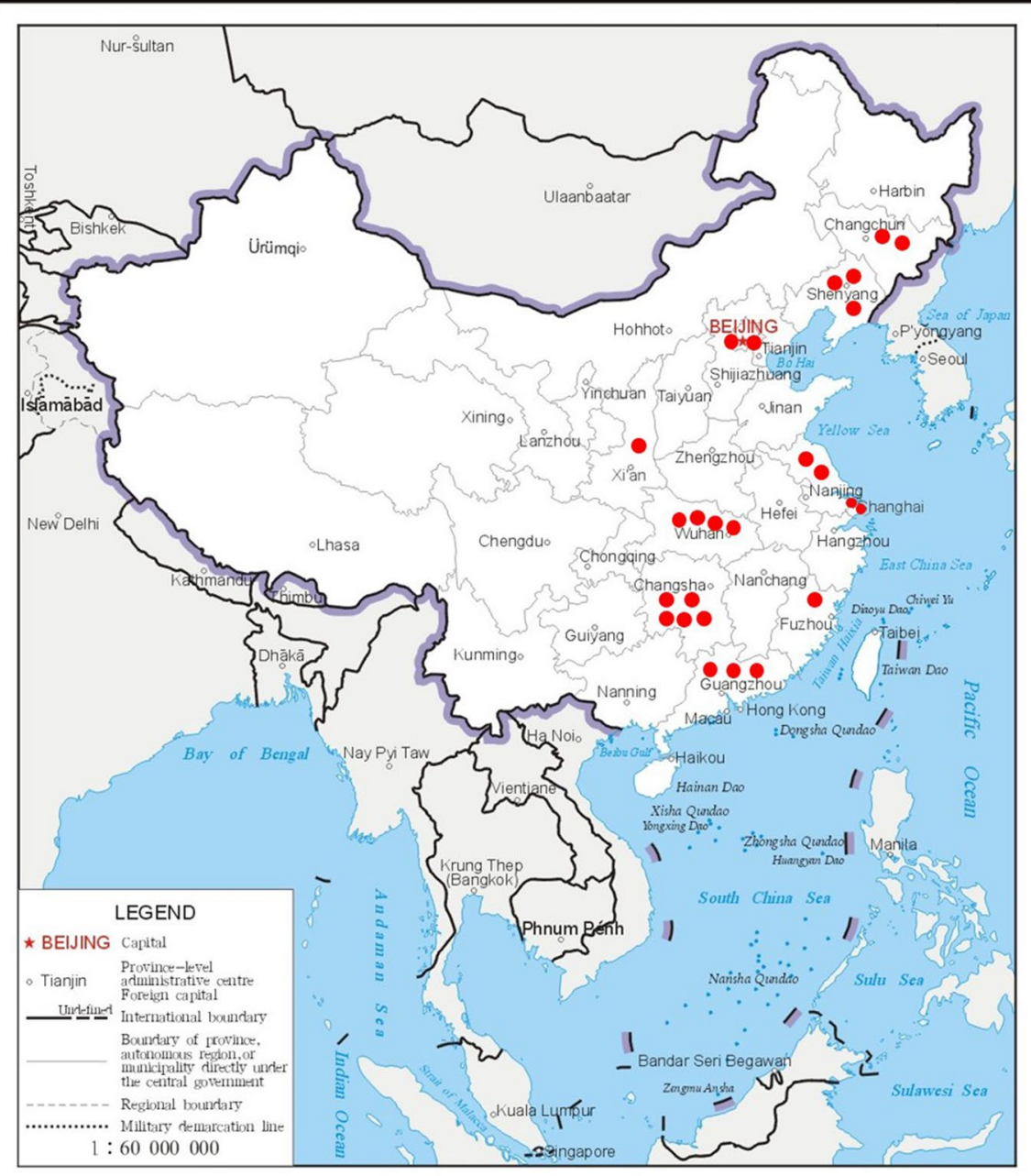

Fig. 1. The distribution of 20 Chinese universities providing selected MOOCs

Press, Xuetangx (www.xuetangx.com) by Tsinghua University, and CNMOOC (www.cnmooc.org) by Shanghai Jiao Tong University.

Additionally, considering that learners of different English levels may exert certain influence on research results, the researcher uniformly selected the courses designed for learners with basic English level. In addition, due to the absence of physical students, the impact from lecturer-student interaction at different degrees can be excluded.

Table 2 presents the detailed information of selected courses which are divided into five course types including English for General Purposes (the courses for integrated skills in English but with reading as the main part), English for Occupational Purposes (the courses for knowledge and skills required by specific occupations), 


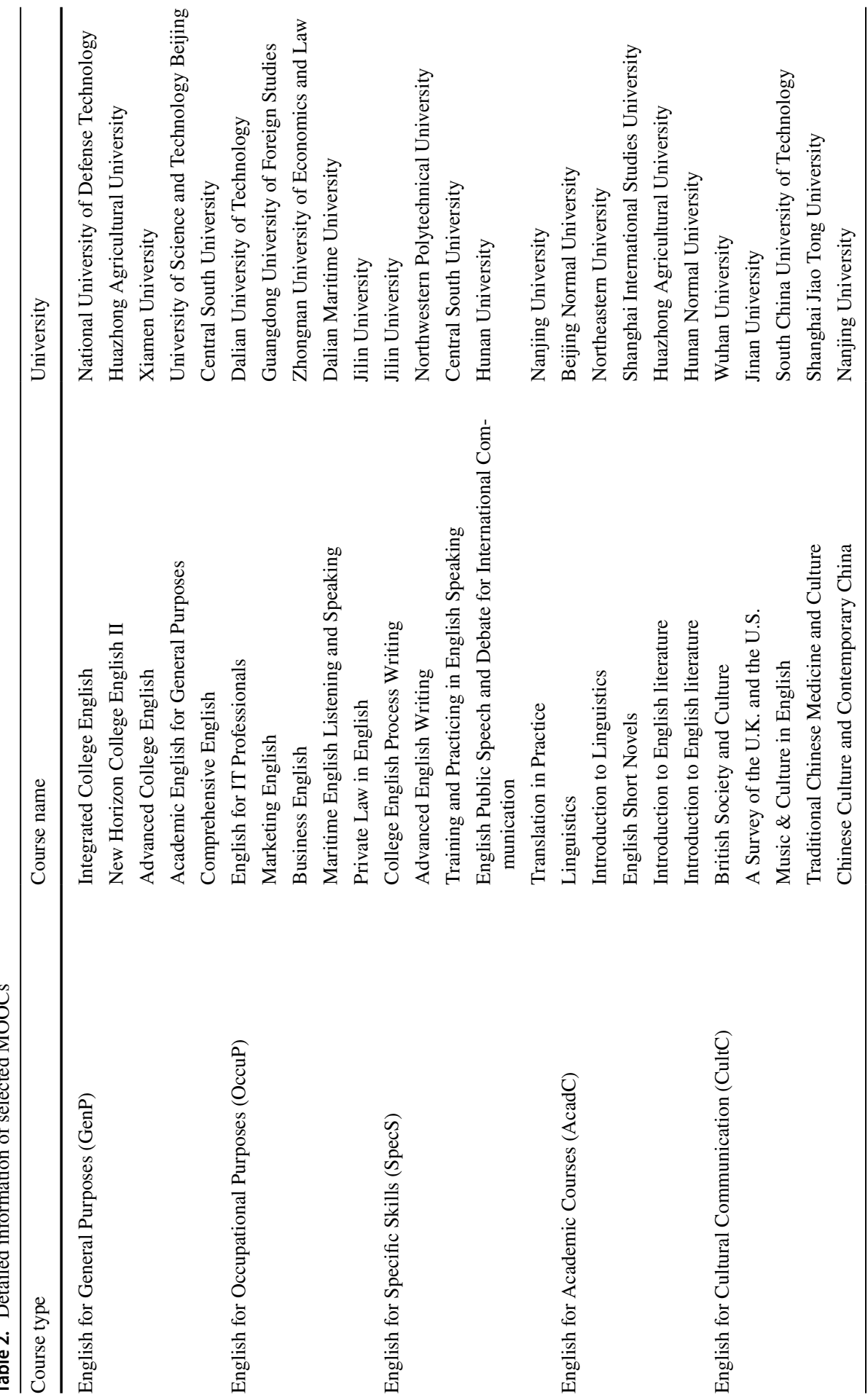




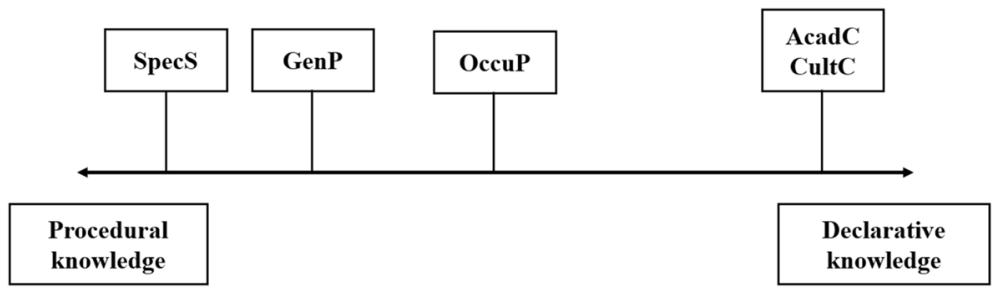

Fig. 2. The five course types' positions on the continuum of procedural-declarative knowledge

English for Specific Skills (the courses for the improvement of language skills), English for Academic Courses (the courses for introducing the language itself and western literature), and English for Cultural Communication (the courses for communicating knowledge about Chinese and western culture), which will be abbreviated as GenP, OccuP, SpecS, AcadC, CultC hereinafter.

These course types can be further distinguished from the perspective of knowledge classification put forward by John R. Anderson. For the research purpose, we set a continuum with the two sorts of knowledge on the two ends. Figure 2 presents the relative positions of five course types in this study on the continuum. Since SpecS attaches much importance to the acquisition or improvement of a certain skill including listening, speaking, writing, and translation, this course type mainly focuses on procedural knowledge which is related to how to perform tasks (Anderson 2009: 205-207). Similar to SpecS, GenP also aims at improving learners' skills, but its main content is intensive reading including both textual analysis and reading practice as well as the introduction of western culture. Thus, in contrast to SpecS, GenP is relatively closer to the other end of the continuum, declarative knowledge focusing on explicit knowledge of various facts (Ibid). However, AcadC and CultC are the right-most ones on the continuum due to their main focus on static and descriptive knowledge around linguistics, literature or Chinese and western culture. The last category, OccuP is positioned almost in the middle of the continuum, referring to its combination of both sorts of knowledge on professional knowledge and specific skills required by a certain occupation.

To take a closer look on each course type, Table 3 presents the general situation of the corresponding sub-corpora across course types. It can be found that each subcorpus includes 8-12 lecturers respectively contributing around 20 minutes' lecture about 2100-2300 words.

Table 3. Description of sub-corpus across course types

\begin{tabular}{llllll}
\hline & GenP & OccuP & SpecS & AcadC & CultC \\
\hline No. of lecturers & 8 & 8 & 8 & 9 & 12 \\
Average time (min) & 20.81 & 21.81 & 20.81 & 22.61 & 23.67 \\
Average length (words) & $2,224.75$ & $2,191.25$ & 2,264 & $2,159.30$ & $2,338.25$ \\
Total Tokens (words) & 17,798 & 17,530 & 18,112 & 19,434 & 28,059 \\
\hline
\end{tabular}




\section{Procedure and Reliability}

After course selection, the research has carried out the process of transcription, annotation, and statistical analysis. The first-round transcription has been completed through speech-to-text processing on www.iflyrec.com. Then, the transcription has been manually proofread to retain its authenticity. Manual annotation is finished with reference to the list of metadiscursive items in Hyland's work (2005a: 218-224) and later verified by the other researcher. Correlations (Spearman's rho) between the two researchers' result is 0.93 , representing a relatively high reliability in annotation. In this phase, we have met some difficulties. For example, some items can function as both metadiscourse and general propositional items and even the same metadiscursive item can present different functions. Under all these circumstances, the identification has been finished according to their specific context and main function. During statistical analysis, the researcher has adopted AntConc 3.5.7 (2018) to obtain raw frequency for Chi-square test of independence carried by IBM SPSS 23. To avoid the influence brought by external factors, this research mainly focuses on the differences with $p$-value at the level of $p<0.01$ (annotated with $* *$ ) and $p<0.001(* * *)$. Accompanying statistical result, detailed observation on concordance lines is also adopted based on Hyland's interpretation on metadiscourse to find out specific functions of metadiscourse in MOOCs.

\section{Results and Discussion}

Since all the research materials are collected from MOOCs without face-to-face interviews with lecturers and learners, the analysis is based on the general principle of result analysis in corpus-based research, which includes the assistance of objective data results and specific context, reference to related analytical framework and previous studies, and avoidance of overgeneralization.

\section{General Distribution of Metadiscourse in CCUM}

From Table 4 which presents the general distribution of metadiscourse in CCUM, it can be found that the CCUM lecturers' metadiscourse distribution covers practically all the categories in Hyland's interpersonal model, but its frequency (72.82 per thousand words, abbreviated as "ptw" thereafter) is much lower than that in Lee and Subtirelu's research on university lectures in classroom teaching (152.06 ptw). This is probably because the brevity of MOOCs requires lecturers to convey more substantial content in limited periods. Another reason can be that the invisibility of learners in MOOCs suppresses the demand for more metadiscourse in mutual interaction.

As for the two dimensions, it can be found that interactional metadiscourse (44.06 ptw, 60.50\%) appears more frequently than interactive one (28.76 ptw, $39.50 \%$ ), which is similar to Lee and Subtirelu's findings (2015: 57) that the ratio of two dimensions (interactive metadiscourse $84.15 \mathrm{ptw}$; interactional metadiscourse 
Table 4 The general distribution of metadiscourse in CCUM

\begin{tabular}{lllll}
\hline Dimension & Category & Raw freq. & Norm. freq. & Prop. (\%) \\
\hline Interactive metadiscourse & Transition Markers & 1183 & 11.72 & 16.10 \\
& Frame Markers & 1098 & 10.88 & 14.94 \\
& Endophoric Markers & 158 & 1.57 & 2.15 \\
& Evidentials & 98 & 0.97 & 1.33 \\
& Code Glosses & 366 & 3.63 & 4.98 \\
Interactional metadiscourse & Total & $\mathbf{2 9 0 3}$ & $\mathbf{2 8 . 7 6}$ & $\mathbf{3 9 . 5 0}$ \\
& Hedges & 702 & 6.96 & 9.55 \\
& Boosters & 321 & 3.18 & 4.37 \\
& Attitude Markers & 143 & 1.42 & 1.95 \\
& Self mentions & 136 & 1.35 & 1.85 \\
& Engagement Markers & 3145 & 31.16 & 42.79 \\
& Total & $\mathbf{4 4 4 7}$ & $\mathbf{4 4 . 0 6}$ & $\mathbf{6 0 . 5 0}$ \\
& & $\mathbf{7 3 5 0}$ & $\mathbf{7 2 . 8 2}$ & $\mathbf{1 0 0}$ \\
\hline
\end{tabular}

Bold and italic represent the total number of a certain category, which is aimed to distinguish the data for the subcategories from the data for categories

$127.36 \mathrm{ptw}$ ) almost reaches 2:3. Figure 3 presents the distribution of ten categories from the most frequently-used one to the least one in anticlockwise direction: engagement markers, transition markers, frame markers, hedges, code glosses, boosters, endophoric markers, attitude markers, self mentions, and evidentials.

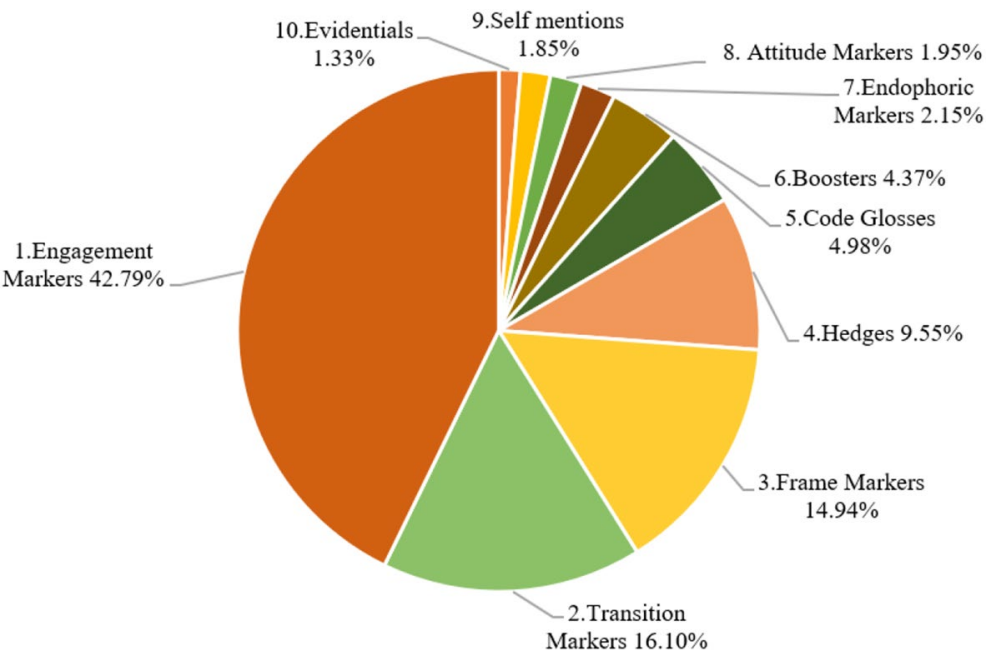

Fig. 3. Proportion ranking of different categories of metadiscourse in CCUM 
1. Interactive dimension

In interactive dimension, transition markers and frame markers are used most often due to their important role in guiding learners through the courses, followed by code glosses, endophoric markers, and evidentials.

Transition markers (11.72 ptw 16.10\%) are used mainly to help learners to grasp sentential logic, including the relation of comparison (4.16 ptw), consequence (4.03 ptw), and addition (3.53 ptw). Lecturers' tendency in using but (1.67 $\mathrm{ptw})$ and however (1.26 ptw) indicates their inclination to focus on adversative relations to highlight key points (see Example 1). Besides, the usage of so (1.65 ptw), as shown in Example 2, suggests lecturers' tendency to adopt inductive method in reasoning, namely, to present evidence before drawing conclusions.

(1) In the next few minutes, some sentences from text A will be analyzed in detail. But before we begin, two things need to be stressed.

(2) Sometimes they look even more convincing than logical arguments, so we need to present them in a wise way.

Frame markers (10.88 ptw $14.94 \%$ ) are mainly used to quickly inform learners of the layout of lectures especially by markers for sequencing (4.84 ptw) to enumerate key points in sequence. On the other hand, markers for shifting topics (2.78 ptw) are used to help lecturers make discourse flow naturally and smoothly. For example:

(3) The first one is immediate action situation .... The next one is delayed action situation... The third one is person missing situation.

(4) Now it's time to listen to some famous R\&B songs.

Besides, markers for announcing goals (2.44 ptw) are usually used at the beginning of the lecture to inform learners of main content to be covered later, which can, to a certain degree, help learners get ready for study. This subcategory is often used in the structure of In this lesson, we will.... Accounting for the smallest proportion in this category, frame makers for labelling stages $(0.81 \mathrm{ptw})$ in CCUM are mainly used to review previous content at the end of lectures.

(5) Basically, here are three types of albums: live, solo, tribute or cover.

(6) In conclusion, Kate Chopin expresses the oppression on women with her extensive use of situational and dramatic ironies throughout the story.

Another helpful category assisting learners' understanding is code glosses which are used as examples (1.81 ptw, 50.00\%), defining (1.19 ptw, 32.79\%), and rephrasing (0.62 ptw, 17.21\%). This category explicitly reflects lecturers' consideration and prediction on learners' prior knowledge and experiences. Among three subcategories, giving examples is the most effective method in making propositions more intelligible. Thus, it appears most frequently in this category probably because lecturers want to enable learners to understand lectures efficiently in MOOCs.

(7) The relieved officer shall introduce to the relieving officer the relative matters at present, such as the ship's course, position, vessel nearby, ...

(8) Originally, a bulldog refers to a muscular heavy dog with a wrinkled face and a distinctive pushed-in nose. 
(9) Barristers are governed by the General Council of the Bar, known as the Bar Council and Inns of Court.

In CCUM, endophoric markers (1.57 ptw, 2.15\%) present a comparatively low frequency. This category underscores certain material in speech to provide scaffolding for learners' understanding. Lecturers usually adopt in the following (...) $(0.43 \mathrm{ptw})$ to get learners prepared for the things yet to come and in this lesson/part/sentence... (0.30 ptw) to review earlier material to convey more detailed analysis.

(10) In the following lessons, we will look at many more examples and talking about greater detail on the understanding of word meanings in translation.

(11) In this lesson, we have gone over how vessels shall navigate in a traffic separation scheme.

The category of evidentials $(0.97 \mathrm{ptw}, 1.33 \%)$ is vital in assisting lecturers to recognize the ownership of thoughts to show respect to original authors. More importantly, lecturers also use this category to seek for sound evidence from authoritative sources to provide a relatively reliable basis for their claims. However, this category ranks the last one in the proportion distribution of the whole usage. This may lie in the reason that much of the information is shared by disciplinary communities (Lee and Subtirelu 2015: 59).

(12) The poem was not completed, but according to Byron, Don Juan was originally supposed to fight and die in the French revolution.

2. Interactional dimension

Interactional metadiscourse plays a vital role in involving learners in courses, with engagement markers (31.16 ptw $42.79 \%)$ as the most frequent category but self mentions the least frequent one.

For lecturers, the main purpose of adopting engagement markers is perhaps to construct affiliation in invisible interaction with learners in MOOCs. This category mostly appears in the form of addressee-oriented pronoun you (8.91ptw) and inclusive we (6.59 ptw), For example:

(13) The word 'fiddle' can also be used as a verb, but in this case, we are looking at a fiddle and you will see the difference.

Meanwhile, rhetorical questions (3.64 ptw) are also used frequently to elicit topic, draw learners' attention to important issues, and steer the development of lectures, while minimal questions (0.24 ptw) including brief questions and tag questions are mainly used to seek for learners' agreement and to make prediction on learners' response as shown in Example 14 and 15.

(14) It's so vital for all of us to stay healthy for the survival of our species. This is indeed humanism, isn't it?

(15) So always remember practice makes perfect. Sounds cliché? But it is the truth.

Directives, similarly, can directly guide learners to focus on certain issues, especially in the form of referential acts (1.81 ptw) to draw learn- 
ers' attention to certain sentences, specific examples, and audio-visual material to assist understanding on content. Moreover, compared with emphatic (0.63 ptw) and cognitive acts $(0.59 \mathrm{ptw})$, lecturers are more inclined to use physical directives $(1.83 \mathrm{ptw})$ to present the appropriate approaches of fulfilling tasks in realistic life. For example:

(16) Finally, let's take a look at (referential act) the cargo handling gears.

(17) But pay attention (emphatic act), catch is turned to its past participle caught, which indicates passive voice.

(18) Imagine (cognitive act) for a moment how dull the world would be if there were only one word to voice a particular thought.

(19) Try (physical act) different approaches to see which one is best for you, but always check (physical act) your introduction before you turn in your final paper.

Additionally, the frequent usage of hedges (6.96 ptw 9.55\%) probably indicates the lecturers' tendency to establish reliability, which may be aroused by high openness of MOOCs. Further investigation has found that the lecturers in CCUM are apt to use hedges to bring accuracy to discourse by means of adverbs, adjectives, and modal verbs expressing uncertainty. Meanwhile, this paper holds the view that the hedges you may/might ask/ find/see... and I think/guess/assume you ... (0.32 ptw) can be seen as a kind of anticipation-oriented hedges (see Example 21) since they are principally aimed at anticipating learners' prior knowledge and possible response, which may help lecturers organize content in a more effective way. This may be, to a great extent, closely related to the invisibility of learners in MOOCs.

(20) To varying degrees, almost every piece of short story means differently to different readers, depending on their age, education and gender.

(21) Now you may ask me: "Alice, how can I control my nervousness?"

As the opposite of hedges, boosters (3.18 ptw, 4.37\%) account for comparatively smaller proportion than hedges. However, in contrast to conveying lecturers' conviction on certain points, boosters in CCUM are more often used to invoke learners' common sense or to encourage them to stand on lecturers' sides. This usage is usually collocated with addresseeoriented engagement markers you and we. For instance:

(22) We all know that language is mainly used to express meaning and we all know how to express meaning through language.

Moreover, boosters also usually co-occur with hedges to mitigate the imposition force on learners even when lecturers express their firm opinions, as shown in Example 23. Lecturers' preference to hedges and prudence in boosters, to some extent, reflect their consideration of learners' vital role in invisible interaction in MOOCs.

(23) Instead of attending Ballyhoo, Lala preferred to stay at home and write a novel. There is no doubt that she's more or less (hedge) discontent with this cold and hostile society.

Similar to Lee and Subtirelu's study, attitude markers (1.42 ptw, 1.95\%) account for a quite low frequency in the overall usage. One of the reasons 
may be that attitude markers can be presented by paralinguistic signals (Lee and Subtirelu 2015: 60). However, the current study presents less frequent usage than previous study, which may be attributed to lecturers' desire to make speech more objective without subjective emotions in MOOCs. In terms of specific items, besides the ones directly expressing lecturers' affective feelings towards content such as interestingly and unfortunately, lecturers tend to use evaluative adjectives with the nature of directives (Hyland 2002: 237), such as it is important/necessary/difficult/easy to..., to prompt learners to realize the importance or necessity of carrying out certain action or the degree of difficulty of certain tasks. For example:

(24) As we know, a title usually serves as the manifestation of the theme, which controls the whole article, so it's very important to understand the title in order to get the theme.

Compared with Lee and Subtirelu's research where self mentions reach 22.47 ptw in university lectures (2015: 57), the frequency of this category in MOOCs $(1.35 \mathrm{ptw}, 1.85 \%)$ is quite low possibly because the invisibility of learners in MOOCs reduce lecturers' demand for frequent interaction with learners. Alternatively, lecturers intend to make their speech more formal. In this study, self mentions are usually collocated with frame markers for announcing goals (see Example 25) to introduce the following content of lectures and sometimes are used by lecturers to provide instruction or suggestions for learners in performing tasks.

(25) I would like to give you some examples of what these types of plagiarism look like. All the examples that I am about to share with you come from the Georgetown University Honor Council Website.

In addition, lecturers also use self mentions to share their experiences in face-to-face teaching or indicate one's speculation, conviction or attitude in the combination with hedges, boosters, and attitude markers such as think, guess, assume, know, believe, hope, etc. For example:

(26) Before they took part in this speaking contest of Hunan Province, they had all gone through $\boldsymbol{m y}$ face to face "sweet torture" for more than 500 hours.

(27) I guess so many of us might have this kind of feelings before, especially after each examination. Right?

\section{Differences in Metadiscourse Across Course Types}

Besides the general pattern of metadiscourse in CCUM, further analysis has found that there are obvious differences in EFL lecturers' metadiscourse pattern across course types. The following tables respectively present the metadiscursive patterns of different course types and the comparative results from the aspect of overall usage, interactive dimension and interactional dimension.

Table 5 presents the distribution of all the categories and sub-categories of metadiscourse. 
Table 5 The distribution of metadiscourse across course types

\begin{tabular}{|c|c|c|c|c|c|}
\hline \multirow[t]{2}{*}{ Category } & \multicolumn{5}{|c|}{ Normalized frequency (ptw) } \\
\hline & GenP & OccuP & SpecS & AcadC & CultC \\
\hline \multicolumn{6}{|l|}{ Transition Markers } \\
\hline $\mathrm{Tad}$ & 2.92 & 3.19 & 3.92 & 3.40 & 3.96 \\
\hline $\mathrm{Tcm}$ & 3.71 & 2.68 & 4.58 & 5.61 & 4.10 \\
\hline Ten & 3.54 & 3.59 & 6.63 & 3.96 & 3.03 \\
\hline Total & 10.17 & 9.47 & 15.13 & 12.97 & 11.08 \\
\hline \multicolumn{6}{|l|}{ Frame Markers } \\
\hline Fse & 8.93 & 4.85 & 6.46 & 2.11 & 3.14 \\
\hline Fst & 0.62 & 1.20 & 1.38 & 0.41 & 0.61 \\
\hline Fgo & 1.80 & 2.34 & 4.20 & 2.01 & 2.07 \\
\hline Ftp & 4.33 & 1.37 & 6.29 & 1.18 & 1.53 \\
\hline Total & 15.68 & 9.75 & 18.33 & 5.71 & 7.34 \\
\hline Endophoric Markers & 2.30 & 1.48 & 2.10 & 1.34 & 0.96 \\
\hline Evidentials & 1.29 & 0.40 & 0.33 & 1.29 & 1.32 \\
\hline \multicolumn{6}{|l|}{ Code Glosses } \\
\hline $\mathrm{Ce}$ & 1.85 & 2.00 & 2.37 & 1.85 & 1.28 \\
\hline $\mathrm{Cd}$ & 1.07 & 1.60 & 0.83 & 1.08 & 1.35 \\
\hline $\mathrm{Cr}$ & 0.62 & 0.74 & 0.28 & 0.77 & 0.68 \\
\hline Total & 3.54 & 4.34 & 3.48 & 3.70 & 4.63 \\
\hline Hedges & 5.67 & 7.07 & 7.01 & 6.69 & 7.80 \\
\hline Boosters & 2.75 & 2.34 & 4.31 & 4.17 & 2.57 \\
\hline Attitude Markers & 1.46 & 1.37 & 1.77 & 0.82 & 1.64 \\
\hline Self mentions & 1.07 & 0.57 & 4.25 & 0.46 & 0.75 \\
\hline \multicolumn{6}{|l|}{ Engagement Markers } \\
\hline Egq & 5.39 & 2.97 & 5.74 & 3.55 & 2.49 \\
\hline Egd & 5.11 & 6.05 & 11.43 & 1.23 & 2.14 \\
\hline Egf & 13.09 & 7.70 & 19.10 & 7.31 & 4.92 \\
\hline Egs & 14.33 & 15.52 & 32.69 & 2.52 & 3.99 \\
\hline Total & 37.93 & 32.23 & 68.96 & 14.61 & 13.54 \\
\hline Interactive dimension & 32.98 & 25.44 & 39.37 & 25.01 & 25.34 \\
\hline Interactional dimension & 48.88 & 43.58 & 86.30 & 26.76 & 26.30 \\
\hline Total metadiscourse & 81.86 & 69.02 & 125.66 & 51.76 & 51.64 \\
\hline
\end{tabular}

Bold and italic represent the total number of a certain category, which is aimed to distinguish the data for the subcategories from the data for categories

As the table shows, all the course types present their own typical patterns of metadiscourse usage while only OccuP shares a similar pattern with CCUM.

Table 6 gives the statistical results of the comparation of general metadiscourse across course types.

With regard to the total metadiscourse, among the five course types, SpecS ranks the first according to the statistical results shown in Table 6: SpecS $>$ GenP $>$ OccuP $>$ AcadC $=$ CultC. The observation on the other two parts in Table 6 also finds 
Table 6 Comparative results ( $p$-value) of general metadiscourse across course types

\begin{tabular}{|c|c|c|c|c|c|}
\hline & GenP & OccuP & SpecS & AcadC & CultC \\
\hline \multicolumn{6}{|l|}{ Total } \\
\hline GenP & I & $0.000 * * *(+)$ & $0.000 * * *(-)^{\mathrm{a}}$ & $0.000 * * *(+)$ & $0.000 * * *(+)$ \\
\hline OccuP & I & / & $0.000 * * *(-)$ & $0.000 * * *(+)$ & $0.000 * * *(+)$ \\
\hline SpecS & I & I & I & $0.000 * * *(+)$ & $0.000 * * *(+)$ \\
\hline AcadC & I & / & I & I & 0.952 \\
\hline CultC & I & I & I & I & I \\
\hline \multicolumn{6}{|c|}{ Interactive } \\
\hline GenP & I & $0.000 * * *(+)$ & $0.001 * *(-)$ & $0.000 * * *(+)$ & $0.000 * * *(+)$ \\
\hline OccuP & I & / & $0.000 * * *(-)$ & 0.790 & 0.946 \\
\hline SpecS & l & l & I & $0.000 * * *(+)$ & $0.000 * * *(+)$ \\
\hline AcadC & I & I & I & I & 0.821 \\
\hline CultC & I & I & I & I & I \\
\hline \multicolumn{6}{|c|}{ Interactional } \\
\hline GenP & l & 0.018 & $0.000 * * *(-)$ & $0.000 * * *(+)$ & $0.000 * * *(+)$ \\
\hline OccuP & I & I & $0.000 * * *(-)$ & $0.000 * * *(+)$ & $0.000 * * *(+)$ \\
\hline SpecS & I & l & I & $0.000 * * *(+)$ & $0.000 * * *(+)$ \\
\hline AcadC & I & I & I & I & 0.761 \\
\hline CultC & / & I & I & l & I \\
\hline
\end{tabular}

${ }^{a}(+) /(-)$ : the sub-corpus on the left column uses certain category of metadiscourse more $(+)$ or less $(-)$ frequently than the one in the upper line

$* * / * * *$ : the $p$-value in Chi-square test is significant at the level of $p<0.01 / p<0.001$

the similar ranking: interactive metadiscourse $(\mathrm{SpecS}>\mathrm{GenP}>\mathrm{OccuP}=\mathrm{AcadC}$ $=$ CultC) and interactional metadiscourse $(\operatorname{SpecS}>\mathrm{GenP}=\mathrm{OccuP}>\mathrm{AcadC}=$ CultC). Specifically speaking, the differences among the five course types chiefly appear in transition markers, frame markers, evidentials, boosters, self mentions, and engagement markers.

\section{Transition Markers}

In the discussion on transition markers, Table 7 shows the comparative results across five course types from the aspect of overall usage and the subcategories including transition markers for addition (Tad), comparison (Tcm), and consequence (Tcn).

The table indicates that transition markers are used most frequently in SpecS and there is almost no evident difference among the other sub-corpora. The only noteworthy point is that the reason why there is no difference in the comparison of SpecS-AcadC, GenP-AcadC and CultC-AcadC at the same time is that the frequency of AcadC is located in the middle in the ranking of five sub-corpora as illustrated in Table 5. In order to find out the course type which adopts transition markers most commonly, this research needs to choose SpecS which presents more differences in comparison with other course types. Moreover, further 
Table 7 Comparative results ( $p$-value) of transition markers across course types

\begin{tabular}{|c|c|c|c|c|c|}
\hline & GenP & OccuP & SpecS & AcadC & CultC \\
\hline \multicolumn{6}{|l|}{ Total } \\
\hline GenP & I & 0.505 & $0.000 * * *(-)$ & 0.012 & 0.354 \\
\hline OccuP & I & l & $0.000 * * *(-)$ & $0.001 * *(-)$ & 0.099 \\
\hline SpecS & I & I & 1 & 0.075 & $0.000 * * *(+)$ \\
\hline AcadC & I & I & I & I & 0.062 \\
\hline CultC & I & / & I & I & I \\
\hline \multicolumn{6}{|l|}{$\mathrm{Tad}$} \\
\hline GenP & I & 0.642 & 0.105 & 0.416 & 0.070 \\
\hline OccuP & I & I & 0.250 & 0.736 & 0.190 \\
\hline SpecS & I & I & I & 0.400 & 0.952 \\
\hline AcadC & I & I & I & I & 0.325 \\
\hline CultC & l & I & l & l & I \\
\hline \multicolumn{6}{|l|}{$\mathrm{Tcm}$} \\
\hline GenP & l & 0.087 & 0.198 & $0.007 * * *(-)$ & 0.516 \\
\hline OccuP & I & 1 & $0.003 * *(-)$ & $0.000 * * *(-)$ & 0.013 \\
\hline SpecS & I & I & I & 0.164 & 0.437 \\
\hline AcadC & I & l & I & I & 0.018 \\
\hline CultC & I & I & I & I & I \\
\hline \multicolumn{6}{|l|}{$T c n$} \\
\hline GenP & l & 0.932 & $0.000 * * *(-)$ & 0.506 & 0.348 \\
\hline OccuP & I & I & $0.000 * * *(-)$ & 0.565 & 0.303 \\
\hline SpecS & I & I & I & $0.000 * * *(+)$ & $0.000 * * *(+)$ \\
\hline AcadC & I & I & I & I & 0.086 \\
\hline CultC & I & I & l & I & I \\
\hline
\end{tabular}

$* * / * * *$ : the $p$-value in Chi-square test is significant at the level of $p<0.01 / p<0.001$

analysis on sub-categories presents that the result is caused by SpecS's most frequent usage of the markers for consequence to explain the reasons why skill practice needs to be completed in a certain way.

\section{Frame Markers}

Table 8 presents the comparative results of overall usage of frame markers across course types and also involves the analysis on the subcategories including frame markers for sequencing (Fse), labelling stages (Fst), announcing goals (Fgo) and shifting topics (Ftp).

From this table, it has been found that SpecS and GenP employ frame markers comparatively more often than the other types. After taking a closer look, we have found that frame markers for announcing goals and shifting topics are most frequently used in SpecS to inform learners of the composition of the following 
Table 8 Comparative results ( $p$-value) of frame markers across course types

\begin{tabular}{|c|c|c|c|c|c|}
\hline & GenP & OccuP & SpecS & AcadC & CultC \\
\hline \multicolumn{6}{|l|}{ Total } \\
\hline GenP & I & $0.000 * * *(+)$ & 0.052 & $0.000 * * *(+)$ & $0.000^{* * *} *(+)$ \\
\hline OccuP & I & I & $0.000 * * *(-)$ & $0.000 * * *(+)$ & $0.006^{* *} *(+)$ \\
\hline SpecS & I & I & 1 & $0.000 * * *(+)$ & $0.000^{* * *}(+)$ \\
\hline AcadC & I & I & I & I & 0.032 \\
\hline CultC & I & I & I & l & I \\
\hline \multicolumn{6}{|l|}{ Fse } \\
\hline GenP & I & $0.000 * * *(+)$ & $0.007 * *(+)$ & $0.000 * * *(+)$ & $0.000 * * *(+)$ \\
\hline OccuP & I & I & 0.043 & $0.000 * * *(+)$ & $0.004^{* *}(+)$ \\
\hline SpecS & I & I & / & $0.000 * * *(+)$ & $0.000 * * *(+)$ \\
\hline AcadC & I & I & l & I & 0.035 \\
\hline CultC & I & I & I & l & I \\
\hline \multicolumn{6}{|l|}{ Fst } \\
\hline GenP & I & 0.070 & 0.022 & 0.378 & 0.959 \\
\hline OccuP & I & 1 & 0.632 & $0.007 * *(+)$ & 0.033 \\
\hline SpecS & I & I & I & $0.002 * *(+)$ & $0.007 * *(+)$ \\
\hline AcadC & I & I & I & I & 0.364 \\
\hline CultC & I & I & I & I & 1 \\
\hline \multicolumn{6}{|l|}{ Fgo } \\
\hline GenP & I & 0.263 & $0.000 * * *(-)$ & 0.645 & 0.526 \\
\hline OccuP & I & I & $0.002 * *(-)$ & 0.493 & 0.544 \\
\hline SpecS & I & I & I & $0.000 * * *(+)$ & $0.000 * * *(+)$ \\
\hline AcadC & I & I & I & I & 0.886 \\
\hline CultC & I & l & I & l & 1 \\
\hline \multicolumn{6}{|l|}{ Ftp } \\
\hline GenP & I & $0.000 * * *(+)$ & 0.010 & $0.000 * * *(+)$ & $0.000 * * *(+)$ \\
\hline OccuP & I & I & $0.000 * * *(-)$ & 0.617 & 0.658 \\
\hline SpecS & I & I & I & $0.000 * * *(+)$ & $0.000 * * *(+)$ \\
\hline AcadC & I & I & I & I & 0.315 \\
\hline CultC & I & I & I & I & l \\
\hline
\end{tabular}

$* * / * * *$ : the $p$-value in Chi-square test is significant at the level of $p<0.01 / p<0.001$

content and guide them through different points. This is probably because SpecS is more likely to provide learners with suggestions on the procedures of fulfilling certain tasks which are usually composed of several parts. Besides, GenP tends to use frame markers for sequencing and shifting topics more often than the other types probably because lecturers in GenP usually need to dissect texts in reading section by listing out key sentences or questions in order and guiding learners through them. 
Table 9 Comparative results ( $p$-value) of evidentials across course types

\begin{tabular}{llllll}
\hline & GenP & OccuP & SpecS & AcadC & CultC \\
\hline GenP & $/$ & $0.004^{* *}(+)$ & $0.001^{* *}(+)$ & 0.987 & 0.939 \\
OccuP & $/$ & $/$ & 0.737 & $0.004^{* *}(-)$ & $0.002^{* *(-)}$ \\
SpecS & $/$ & $/$ & $/$ & $0.001^{* *}(-)$ & $0.001^{* * *}(-)$ \\
AcadC & $/$ & $/$ & $/$ & $/$ & 0.924 \\
CultC & $/$ & $/$ & $/$ & $/$ & $/$ \\
\hline
\end{tabular}

$* * * * * *$ the $p$-value in Chi-square test is significant at the level of $p<0.01 / p<0.001$

\section{Evidentials}

As for the usage of evidentials, Table 9 presenting the comparative results among different course types indicates that evidentials in AcadC, CultC, and GenP tend to appear more often than in the other course types.

EFL lecturers in AcadC and CultC are most inclined to seek for intertextual support from well-known scholars, distinguished works, or historical legends and mythology, for both of them have close relationship respectively with the academic field in linguistics and literature, culture, and society. This is probably due to the unique knowledge structure of these two course types. As the representative of declarative knowledge, AcadC and CultC presents the obvious feature of horizontal knowledge structure which consists of a series of specialized languages with specialized modes of interrogation and criteria for the construction of texts (Bernstein 1999: 162). In other words, the understanding and transmission of this kind of experiential knowledge, with 'truth' being defined by the 'voice', are conveyed by reference to the knower's subjective or intersubjective attributes and personal experiences (Maton 2000: 157). Thus, lecturers in AcadC and CultC generally cannot quickly establish credibility in MOOCs only by their own words and then it is quite necessary for them to seek for help from citation to demonstrate a plausible basis for one's claims (Hyland 2010: 140). In the same way, this category is also used frequently by GenP where lecturers use evidentials more often to indicate that the text analysis is mainly based on original authors' points or key sentences in texts.

\section{Boosters}

In terms of boosters, Table 10 compares the use of boosters in the different sub-corpora.

The table shows that this category is used more often in SpecS and AcadC than in the other types. Further analysis on concordance lines has found that boosters are usually used to invoke learners' commonsense knowledge or seek for their agreement on the method of improving certain skills in SpecS. With regard to AcadC, it has been mentioned that its horizontal knowledge structure guides lecturers in this course type to lay more emphasis on trustworthiness. Therefore, boosters are adopted more often to lead learners to agree with the lecturers' interpretation on language itself and literary works. 
Table 10 Comparative result ( $p$-value) of boosters across course types

\begin{tabular}{llllll}
\hline & GenP & OccuP & SpecS & AcadC & CultC \\
\hline GenP & $/$ & 0.440 & 0.013 & 0.021 & 0.703 \\
OccuP & $/$ & $/$ & $0.001 * *(-)$ & $0.002^{* *}(-)$ & 0.635 \\
SpecS & $/$ & $/$ & $/$ & 0.836 & $0.001 * *(+)$ \\
AcadC & $/$ & $/$ & $/$ & $/$ & $0.002 * *(+)$ \\
CultC & $/$ & $/$ & $/$ & $/$ & $/$ \\
\hline
\end{tabular}

$* *$ : the $p$-value in Chi-square test is significant at the level of $p<$ 0.01

Table 11 Comparative results ( $p$-value) of self mentions across course types

\begin{tabular}{llllll}
\hline & GenP & OccuP & SpecS & AcadC & CultC \\
\hline GenP & $/$ & 0.103 & $0.000^{* * *}(-)$ & 0.034 & 0.259 \\
OccuP & $/$ & $/$ & $0.000^{* * *}(-)$ & 0.649 & 0.478 \\
SpecS & $/$ & $/$ & $/$ & $0.000^{* * *}(+)$ & $0.000^{* * *}(+)$ \\
AcadC & $/$ & $/$ & $/$ & $/$ & 0.224 \\
CultC & $/$ & $/$ & $/$ & $/$ & $/$ \\
\hline
\end{tabular}

***: the $p$-value in Chi-square test is significant at the level of $p<0.001$

\section{Self Mentions}

Although the category of self mentions is generally used uncommonly in CCUM, the comparative results in Table 11 show evidently that self mentions appear most frequently in SpecS.

Based on further analysis, it can be found that lecturers in SpecS usually indicate their presence when telling learners what to be discussed in the combination with frame markers for announcing goals or when sharing their own experience. This may be ascribed to the fact that the focus of SpecS is to improve learners' specific skills, and that the announcement on the following content can effectively help learners grasp the general structure of lecturers' speech, especially the specific steps of doing certain tasks. Also, sharing their own students' performance in face-to-face teaching may arouse learners' motivation to practice.

\section{Engagement Markers}

There are also some noticeable findings on engagement markers. Table 12 presents the overall usage of this category and its subcategories including engagement markers by questions (Egq), directives (Egd), first person (Egf), and second person (Egs).

Table 12 indicates that SpecS has adopted engagement markers most frequently among the five course types, followed by GenP and OccuP, with AcadC and CultC sharing the last place. Table 12 also shows that even in the four sub-categories of engagement markers, SpecS still ranks the first. Then, through further analysis, it 
Table 12 Comparative results ( $p$-value) of engagement markers across course types

\begin{tabular}{|c|c|c|c|c|c|}
\hline & GenP & OccuP & SpecS & AcadC & CultC \\
\hline \multicolumn{6}{|l|}{ Total } \\
\hline GenP & I & $0.004 * *(+)$ & $0.000 * * *(-)$ & $0.000 * * *(+)$ & $0.000 * * *(+)$ \\
\hline OccuP & I & I & $0.000 * * *(-)$ & $0.000 * * *(+)$ & $0.000^{* * *}(+)$ \\
\hline SpecS & I & I & I & $0.000 * * *(+)$ & $0.000 * * *(+)$ \\
\hline AcadC & I & I & I & I & 0.329 \\
\hline CultC & I & I & I & I & I \\
\hline \multicolumn{6}{|l|}{$E g q$} \\
\hline GenP & I & $0.000 * * *(+)$ & 0.658 & $0.007 * *(+)$ & $0.000 * * *(+)$ \\
\hline OccuP & I & 1 & $0.000 * * *(-)$ & 0.326 & 0.343 \\
\hline SpecS & I & I & 1 & $0.002 * *(+)$ & $0.000 * * *(+)$ \\
\hline AcadC & I & I & I & I & 0.036 \\
\hline CultC & I & I & I & I & I \\
\hline \multicolumn{6}{|l|}{$E g d$} \\
\hline GenP & I & 0.239 & $0.000 * * *(-)$ & $0.000 * * *(+)$ & $0.000 * * *(+)$ \\
\hline OccuP & I & 1 & $0.000 * * *(-)$ & $0.000 * * *(+)$ & $0.000 * * *(+)$ \\
\hline SpecS & I & I & I & $0.000 * * *(+)$ & $0.000 * * *(+)$ \\
\hline AcadC & I & I & I & I & 0.021 \\
\hline CultC & I & I & I & I & 1 \\
\hline \multicolumn{6}{|l|}{$E g f$} \\
\hline GenP & I & $0.000 * * *(+)$ & $0.000 * * *(-)$ & $0.000 * * *(+)$ & $0.000 * * *(+)$ \\
\hline OccuP & I & I & $0.000 * * *(-)$ & 0.661 & $0.000 * * *(+)$ \\
\hline SpecS & I & l & I & $0.000 * * *(+)$ & $0.000 * * *(+)$ \\
\hline AcadC & l & I & I & I & $0.001 * * *(+)$ \\
\hline CultC & I & I & I & I & I \\
\hline \multicolumn{6}{|l|}{ Egs } \\
\hline GenP & I & 0.357 & $0.000 * * *(-)$ & $0.000 * * *(+)$ & $0.000 * * *(+)$ \\
\hline OccuP & I & I & $0.000 * * *(-)$ & $0.000 * * *(+)$ & $0.000 * * *(+)$ \\
\hline SpecS & I & I & / & $0.000 * * *(+)$ & $0.000 * * *(+)$ \\
\hline AcadC & I & / & I & I & $0.007 * *(-)$ \\
\hline CultC & I & I & l & l & / \\
\hline
\end{tabular}

$* * / * * *$ : the $p$-value in Chi-square test is significant at the level of $p<0.01 / p<0.001$

is found that SpecS has most frequently adopted physical acts (5.19 ptw) to provide instruction on acts related to real-world and referential acts (3.42 ptw) to draw learners' attention to examples. This may be caused by the similar reason mentioned before that lecturers in SpecS attaches much importance to learners' mastery of procedural knowledge. That is to say, they probably pay attention to conveying the method of completing a certain task and meanwhile closely relate the course content to learners' realistic practices in life. Therefore, they need to provide good guidance for learners by keeping learners' attention and involving them into the pseudo dialogue in MOOCs now and again. 
In addition, Table 12 also tells us that GenP has similarly used engagement markers by questions quite frequently, which is supported by qualitative analysis that lecturers in GenP tend to raise questions to prompt the development of unfolding content and also help learners to have better text comprehension.

\section{Functions of Metadiscourse in CCUM}

Taken as a whole, results from both statistical and descriptive analysis reveal that lecturers' metadiscourse in MOOCs plays a vital role in helping establish harmonious interrelation among lecturers, imagined learners, and course content through various functions as Fig. 4 shows. The figure also indicates that lecturers are more inclined to adopt metadiscourse to construct lecturer-learner and lecturer-content relation than to build learner-content relationship.

Moreover, further analysis presents that these functions are mainly aimed to achieve the enhancement of intelligibility, reliability, and interactivity (see Fig. 5), which is closely related to typical features of MOOCs. For instance, brief lectures in MOOCs lead to the demand for learners' efficient understandings prompted by comprehensive input. Also, it is advisable to avoid setting obstacles in language comprehension for learners in MOOCs where the study is mostly driven by learners' subjective initiative. Moreover, it is noted that metadiscourse for anticipation on learners' prior knowledge and experiences has hardly appeared in other spoken registers possibly because the invisibility of learners makes it more important for lecturers in MOOCs to predict learners' conditions in advance. For these reasons, intelligibility of lectures is one of the most important aims for metadiscursive usage in MOOCs.

The importance attached to reliability is rooted in the influence from the higher openness of MOOCs compared with classroom teaching. Due to the great number of online learners, lecturers are prudent in projecting themselves in courses, such as expressing one's own affective attitude towards content or sharing experiences. In other words, lecturers probably tend to enhance the reliability of speech at certain cost of lecturer-learner interactivity.

Nevertheless, interactivity is indispensable in EFL MOOCs, especially in lecturer-learner and lecturer-content communication. This is probably because MOOCs' large audience brings about lecturers' much attention to stressing the presence of learners. Another point may be that brief lectures require lecturers try to support learners' quick comprehension through smooth interaction between learners and content.

More importantly, lecturers' metadiscourse usage is also inextricably correlated with course types with different knowledge structures. SpecS adopts metadiscourse most frequently to chiefly improve intelligibility and interactivity through the high use of transition markers, frame markers, boosters, self mentions, and engagement markers. Its focus on practical course content requires lecturers to keep learners' attention and relate course content to their skill practice. GenP requires lecturers to stress all the three aspects by adopting frame markers, engagement markers (especially questions for thinking), and evidentials since 

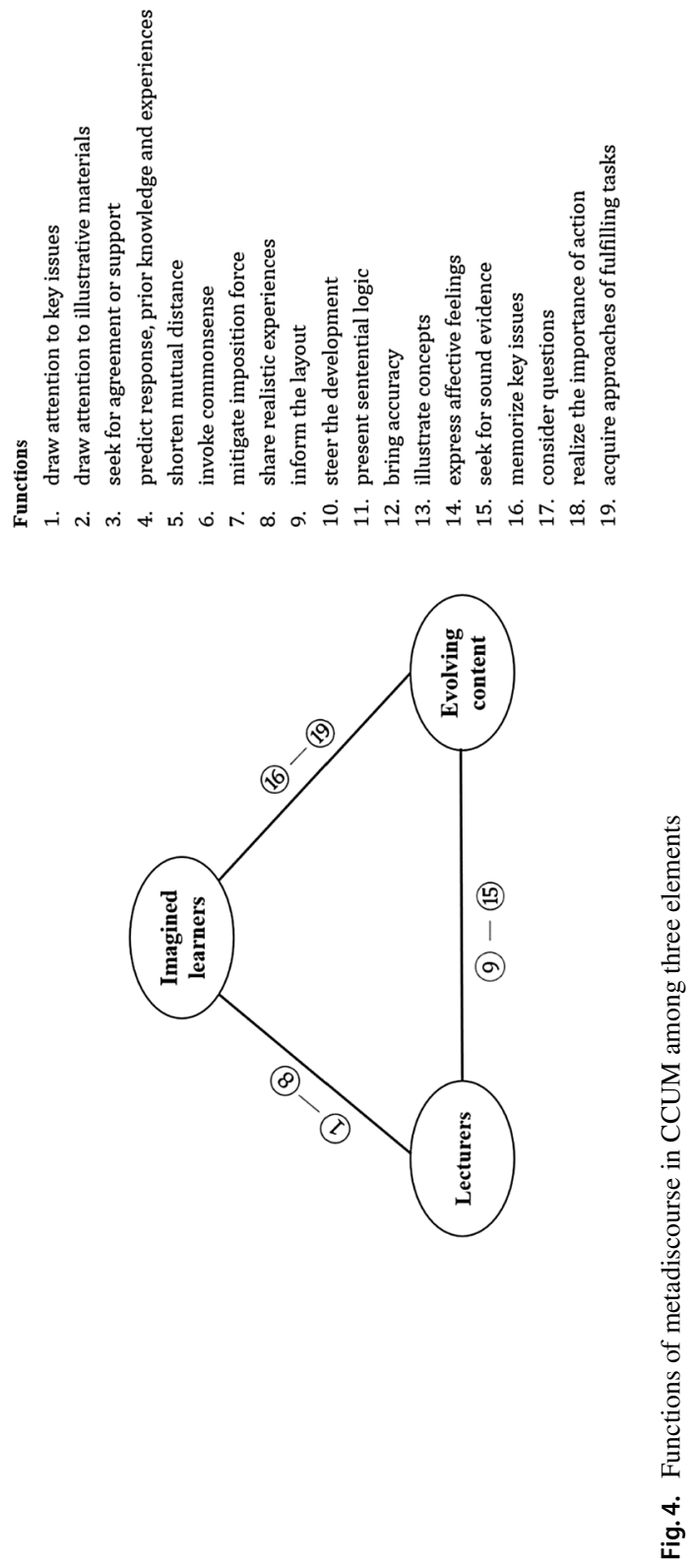


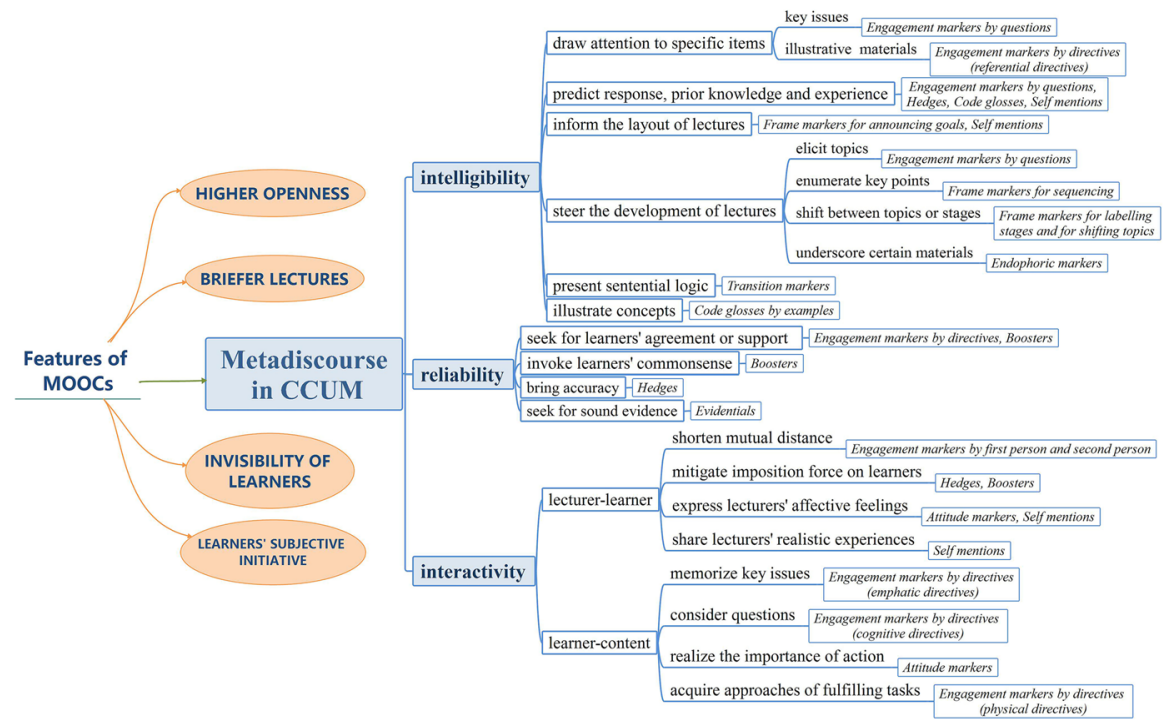

Fig. 5. Categories of metadiscursive functions in CCUM

intensive reading requests lecturers to convey intelligible and credible dissection of texts and meanwhile strengthen learner-content connection. By contrast, AcadC and CultC with the low use of metadiscourse usage mainly concentrate on reliability, caused by their principal focus on declarative knowledge with horizontal knowledge structure and thus they adopt evidentials most frequently for intertextual support. Lastly, due to the focus on both declarative and procedural knowledge in certain occupational field, OccuP presents a similar metadiscourse pattern to CCUM and pay attention to all the three aspects.

\section{Conclusion and Implications}

The present study sought to investigate the general usage of EFL lecturers' meta discourse in Chinese university MOOCs and differences across five-course types. The objective of the study was to prompt the realistic development of MOOC learning in China and to deepen the theoretical exploration in spoken metadiscourse. The study findings reveal that interactive and interactional metadiscourse is used at the ratio of about 2:3 in CCUM, which is still a much lower frequency, compared with thatin faceto-face teaching. A potential reason for this could be that MOOCs require lecturers to offer more substantial content in brief lectures. Besides, other features of MOOCs including higher openness, the invisibility of learners, and the learners' subjective initiative as the main driving force suggest that lecturers emphasize intelligibility and reliability at the cost of interactivity. Additionally, the study found that course types focusing on procedural knowledge concerning practical process enhanced intelligibility and 
interactivity through metadiscourse. The course types focusing on declarative knowledge with a horizontal knowledge structure considered reliability to be more important.

Consequently, the study suggests that lecturers first use metadiscourse by highlighting the typical features of MOOCs. For example, lecturers can lower the frequency of metadiscourse adequately to convey more substantial content in brief lectures. It is also advisable to consider promoting intelligibility, reliability, and interactivity in lectures by fully utilizing different categories of metadiscourse. Moreover, the study on different types of courses indicate that courses emphasizing procedural knowledge can adopt more metadiscourse to guide learners fluently and boost the learner-content interactivity while courses focusing on indeterminate declarative knowledge are supposed to focus on enhancing reliability. The study, however, proposes that the emphasis should be laid on intelligibility and interactivity both in lecturer-learner and learner-content interaction to develop harmonious lecturer-learner affiliation in the latter courses.

Future studies are encouraged to focus more on refining the control of variables including lecturers' age, teaching experience and style to improve research results. Engaging in interviews with lecturers and learners will also contribute to more reliable findings. Besides, the size of the corpus ought to be expanded to increase the validity of research. Future studies may also conduct diachronic research on the changing patterns of metadiscourse in MOOCs.

\section{Appendix}

\section{Metadiscourse items in CCUM}

\begin{tabular}{ll}
\hline Categories & Specific linguistic items \\
\hline Transition markers & $\begin{array}{l}\text { additionally (in addition), again, also, alternatively, and, another, apart from, } \\
\text { besides, furthermore, meanwhile, moreover, what's more; although/though, but, } \\
\text { by contrast/ in contrast to, compared with, despite, even if, however, in spite of, } \\
\text { in the same way, instead (of), just as, likewise/like, on the contrary/contrary to, } \\
\text { otherwise, rather than, similarly/similar to, whereas, while, yet; as, as a result, } \\
\text { as such, because (of), consequently, for, hence, in order to, in that, now that, } \\
\text { since, so, so ... that, so as to, so that, then, thereby, therefore, thus } \\
\text { (the) first/second/third, A/B, another, finally, first of all, firstly, lastly, next, one/ } \\
\text { two/three, the last, then; alright / all right, at this point, in a word, in conclusion, } \\
\text { now, ok, part one/two, so, so far, to summarize, sum up, well; will/be going to, } \\
\text { here/there are + number + questions/reasons/...; come to, move to, now, so, } \\
\text { then, well } \\
\text { above, earlier, here, in the former, in the last ..., in the next ..., in the previous, in } \\
\text { this case/sentence/example, later, (in) the following } \\
\text { according to, argue, as...point out, as the saying goes, assert, claim, consider, } \\
\text { decree, explain, from, it is reported that, produce, said/says, state, suggest, quote } \\
\text { for example, for instance, like, such as; means, refer to; in other words, known as, } \\
\text { namely, that is (to say), very simply put. }\end{array}$ \\
Endophoric markers \\
Evidentials \\
Code glosses
\end{tabular}




\begin{tabular}{ll}
\hline Categories & Specific linguistic items \\
\hline Hedges: & about, almost, apparently, approximately, around, assume, at least, commonly, \\
& estimate, frequently, generally, guess, in general, in many cases, in my opinion, \\
& in some cases, in this sense, in this view, largely, likely, mainly, may, maybe, \\
& might, more or less, most (of), mostly, nearly, not always, often, perhaps, pos- \\
& sible, probably, relatively, seem, seemingly, sometimes, suggest, tend to, think, \\
& usually \\
actually, always, believe, clear, clearly, definite(ly), entirely, evident, in fact, & indeed, indicate, know, must, never, no doubt, obvious(ly), of course, only, \\
Boosters & really, see, show, sure, totally, true, truly, undoubtedly, without doubt. \\
appropriate, amusing, appealing, clear, crucial, deeply, desirable, desperately, \\
difficult, dramatically, easy, effectively, effort-taking, essential, even, fortu- \\
nately, happy, hard, helpful, hope, hopefully, impossible, important, interest- \\
ingly, inspiring, lucky, necessary, outstandingly, preferably, pitiful, remarkably, \\
significant, simple, sophisticated, substantially, tough, unfortunately \\
I, me, my, our (exclusive), we (exclusive). \\
wh-questions, yes/no questions, minimal questions; directives (ask, check, \\
consider, decide, find out, identify, imagine, keep in mind, listen to, look, make, \\
notice, pay attention to, practice, read, remember, see, talk about, think about, \\
watch); you, your, yourself; let's, we (inclusive), our (inclusive), us (inclusive), \\
Engagement markerselves (inclusive)
\end{tabular}

Acknowledgements We would like to express sincere gratitude to the editors who will take charge of our submission and the anonymous reviewers who will provide their insightful and helpful comments.

Funding This work was supported by the Chinese national Project for industry-education cooperation "A Study of the Effectiveness of IFLYTEK FIF APP for Oral Practice on Listening and Speaking Teaching in University" (201802083023).

Code Availability The custom code is available in the paper.

\section{Compliance with Ethical Standards}

Conflict of interest On behalf of all authors, the corresponding author states that there is no conflict of interest.

Availability of Data and Material All data and material are fully available without restriction.

\section{References}

Ädel, A. (2012). What I want you to remember is...: Audience orientation in monologic academic discourse. English Text Construction, 5(1), 101-127. https://doi.org/10.1075/etc.5.1.06ade.

Ágnes, M. G. (2012). Are you with me? A metadiscursive analysis of interactive strategies in college students' course presentations. International Journal of English Studies, 12(1), 55-78. https://doi. org/10.6018/ijes.12.1.118281.

Anderson, J. R. (2009). Cognitive psychology and its implications (7th ed.). New York: Worth Publishers. 
Bernstein, B. (1999). Vertical and horizontal discourse: An essay. British Journal of Sociology of Education, 20(2), 157-173. https://doi.org/10.1080/01425699995380.

Cao, F., \& Hu, G. (2014). Interactive metadiscourse in research articles: A comparative study of paradigmatic and disciplinary influences. Journal of Pragmatics, 66, 15-31. https://doi.org/10.1016/j. pragma.2014.02.007.

Dafouz-Milne, E. (2008). The pragmatic role of textual and interpersonal metadiscourse markers in the construction and attainment of persuasion: A cross-linguistic study of newspaper discourse. Journal of Pragmatics, 40(1), 95-113. https://doi.org/10.1016/j.pragma.2007.10.003.

$\mathrm{Fu}, \mathrm{X} .$, \& Hyland, K. (2014). Interaction in two journalistic genres: A study of interactional metadiscourse. English Text Construction, 7(1), 122-144. https://doi.org/10.1075/etc.7.1.05fu.

Gillaerts, P., \& Velde, F. V. D. (2010). Interactional metadiscourse in research article abstracts. Journal of English for Academic Purposes, 9(2), 128-139. https://doi.org/10.1016/j.jeap.2010.02.004.

Ho, V., \& Li, C. (2018). The use of metadiscourse and persuasion: An analysis of first year university students' timed argumentative essays. Journal of English for Academic Purposes, 33, 53-68. https:// doi.org/10.1016/j.jeap.2018.02.001.

Hong, H., \& Cao, F. (2014). Interactional metadiscourse in young EFL learner writing: A corpusbased study. International Journal of Corpus Linguistics, 19(2), 201-224. https://doi.org/10.1075/ ijcl.19.2.03hon.

Hu, G., \& Cao, F. (2015). Disciplinary and paradigmatic influences on interactional metadiscourse in research articles. English for Specific Purposes, 39, 12-25. https://doi.org/10.1016/j. esp.2015.03.002.

Hyland, K. (1996). Writing without conviction? Hedging in science research articles. Applied Linguistics, 17(4), 433-454. https://doi.org/10.1093/applin/17.4.433.

Hyland, K. (2001). Bringing in the reader: Addressee features in academic articles. Written Communication, 18(4), 549-574. https://doi.org/10.1177/0741088301018004005.

Hyland, K. (2002). Directives: Argument and engagement in academic writing. Applied Linguistics, 23(2), 215-239. https://doi.org/10.1093/applin/23.2.215.

Hyland, K. (2004). Disciplinary interactions: Metadiscourse in L2 postgraduate writing. Journal of Second Language Writing, 13(2), 133-151. https://doi.org/10.1016/j.jslw.2004.02.001.

Hyland, K. (2005a). Metadiscourse: Exploring interaction in writing. London: Continuum.

Hyland, K. (2005b). Stance and engagement: A model of interaction in academic discourse. Discourse Studies, 7(2), 173-192. https://doi.org/10.1177/1461445605050365.

Hyland, K. (2010). Metadiscourse: Mapping interactions in academic writing. Nordic Journal of English Studies, 9(2), 125-143. https://doi.org/10.35360/njes.220.

Hyland, K., \& Jiang, F. (2018). In this paper we suggest: Changing patterns of disciplinary metadiscourse. English for Specific Purposes, 51, 18-30. https://doi.org/10.1016/j.esp.2018.02.001.

Hyland, K., \& Tse, P. (2004). Metadiscourse in academic writing: A reappraisal. Applied Linguistics, 25(2), 156-177. https://doi.org/10.1093/applin/25.2.156.

Intaraprawat, P., \& Steffensen, M. S. (1995). The use of metadiscourse in good and poor ESL essays. Journal of Second Language Writing, 4(3), 253-272. https://doi.org/10.1016/1060-3743(95)90012-8.

Kawase, T. (2015). Metadiscourse in the introductions of PhD theses and research articles. Journal of English for Academic Purposes, 20, 114-124. https://doi.org/10.1016/j.jeap.2015.08.006.

Khedri, M., Heng, C. S., \& Ebrahimi, S. F. (2013). An exploration of interactive metadiscourse markers in academic research article abstracts in two disciplines. Discourse Studies, 15(3), 319-331. https:// doi.org/10.1177/1461445613480588.

Kuhi, D., \& Mojood, M. (2014). Metadiscourse in newspaper genre: A cross-linguistic study of English and Persian editorials. Procedia-Social and Behavioral Sciences, 98, 1046-1055. https://doi. org/10.1016/j.sbspro.2014.03.515.

Lee, J. J., \& Casal, J. E. (2014). Metadiscourse in results and discussion chapters: A cross-linguistic analysis of English and Spanish thesis writers in engineering. System, 46, 39-54. https://doi. org/10.1016/j.system.2014.07.009.

Lee, J. J., \& Deakin, L. (2016). Interactions in L1 and L2 undergraduate student writing: Interactional metadiscourse in successful and less-successful argumentative essays. Journal of Second Language Writing, 33, 21-34. https://doi.org/10.1016/j.jslw.2016.06.004.

Lee, J. J., \& Subtirelu, N. C. (2015). Metadiscourse in the classroom: A comparative analysis of EAP lessons and university lectures. English for Specific Purposes, 37(1), 52-62. https://doi.org/10.1016/j. esp.2014.06.005. 
Li, T., \& Wharton, S. (2012). Metadiscourse repertoire of L1 Mandarin undergraduates writing in English: A cross-contextual, cross-disciplinary study. Journal of English for Academic Purposes, 11(4), 345-356. https://doi.org/10.1016/j.esp.2014.06.005.

Liu, C. (2019). Gender and discipline: Intensifier variation in academic lectures. Corpus Pragmatics, 3(3), 211-224. https://doi.org/10.1007/s41701-019-00057-w.

Maton, K. (2000). Languages of legitimation: The structuring significance for intellectual fields of strategic knowledge claims. British Journal of Sociology of Education, 21(2), 141-167. https://doi. org/10.1080/713655351.

Mauranen, A. (1993). Contrastive ESP rhetoric: Metatext in Finnish-English economics texts. English for Specific Purposes, 12(1), 3-22. https://doi.org/10.1016/0889-4906(93)90024-i.

Mauranen, A. (2010). Discourse reflexivity: A discourse universal? The case of ELF. Nordic Journal of English Studies, 9(2), 13-40. https://doi.org/10.35360/njes.216.

Mu, C., Zhang, L. J., Ehrich, J., \& Hong, H. (2015). The use of metadiscourse for knowledge construction in Chinese and English research articles. Journal of English for Academic Purposes, 20, 135-148. https://doi.org/10.1016/j.jeap.2015.09.003.

Mur-Dueñas, P. (2011). An intercultural analysis of metadiscourse features in research articles written in English and in Spanish. Journal of Pragmatics, 43(12), 3068-3079. https://doi.org/10.1016/j.pragm a.2011.05.002 .

Nunan, D. (1991). Language teaching methodology: A textbook for teachers. New York: Prentice Hall.

Vásquez, C. (2015). Don't even get me started: Interactive metadiscourse in online consumer reviews. In E. Darics (Ed.), Digital business discourse (pp. 19-39). New York: Palgrave Macmillan. https://doi. org/10.1057/9781137405579_2.

Vergaro, C. (2005). "Dear Sirs, I hope you will find this information useful": Discourse strategies in Italian and English 'For Your Information' (FYI) letters. Discourse Studies, 7(1), 109-135. https://doi. org/10.1177/1461445605048769.

Zhang, M., Sun, W., Peng, H., Gan, Q., \& Yu, B. (2017). A multidimensional analysis of metadiscourse markers across spoken registers. Journal of Pragmatics, 117(2), 106-118. https://doi.org/10.1016/j. pragma.2017.06.004.

Publisher's Note Springer Nature remains neutral with regard to jurisdictional claims in published maps and institutional affiliations. 